\title{
A patente como fonte de informação (des)necessária para a Biotecnologia em Saúde
}

\author{
Patents as an (un)necessary source of \\ information for Biotechnology in Health
}

\author{
Fabricia Pires PIMENTA ${ }^{1}$
}

\section{Resumo}

A biotecnologia, principalmente no âmbito da saúde, tem apresentado soluções e oportunidades para a sociedade, contribuindo para grandes desenvolvimentos científicos. Entretanto, o acelerado avanço das pesquisas tem produzido uma intensa quantidade de dados, em diferentes formatos, divulgados por diferentes meios e, por vezes, não utilizados adequadamente pela comunidade científica. Nesse contexto, embora a patente tenha sido considerada uma excepcional fonte de informação científica e tecnológica, desconhece-se como essa tipologia tem sido explorada. O presente trabalho buscou analisar como a comunidade científica acolhe o uso de documentos de patente em seus trabalhos acadêmicos. E, para tal, analisou 556 teses/ dissertaçães dos programas de pós-graduação da Fundação Oswaldo Cruz. Nesse universo amostral, somente 2,87\% dos trabalhos acadêmicos citaram ao menos um documento de patente. Inequivocamente, observou-se que as patentes não são valorizadas pela comunidade científica como fonte para obtenção de conhecimento. A não exploração desse enorme volume de informação implica, especialmente para o Brasil, desperdício de investimentos em Pesquisa, Desenvolvimento e Inovação, ao não se apreciar o que já está posto no estado da arte, culminando em pesquisas repetidas e atraso no desenvolvimento científico e tecnológico do país. Assim, os dados alertam para a necessidade de incentivo ao uso das patentes como importante fonte de informação para a biotecnologia em saúde.

Palavras-chave: Biotecnologia em Saúde. Fonte de informação. Patentes.

\begin{abstract}
Biotechnology, particularly in the health sector, has created solutions and opportunities for society in general, contributing to important scientific developments. However, rapid research achievements produce an intense amount of data in different formats, published in different media, and sometimes not adequately used by the scientific community. Patents have been regarded as an exceptional source of scientific and technological information, but how they have been utilized is unknown. The aim of this study was to analyze how the scientific community uses patent documents in academic work. In order to understand that, 556 thesis/dissertations from graduate programs of the Oswaldo Cruz Foundation were analyzed, of which only 2.87\% of academic thesis/dissertations cited at least one patent document. Clearly, it was observed that the scientific community does not appreciate patents as a source of scientific knowledge. Failure to address this huge volume of information implies, especially for Brazil, that investment in research, development and innovation goes to waste when patent literature is neglected, which results in repeated investigations and consequently, a delay in the scientific and technological development of the country. Thus, the results point out to the need to encourage the use of patents as they are an important source of information for biotechnology in health.
\end{abstract}

Keywords: Biotechnology in health. Information sources. Patents.

\footnotetext{
1 Fundação Oswaldo Cruz, Centro de Desenvolvimento Tecnológico em Saúde, Escritório de Inovação. Av. Brasil, 4036, Prédio da Expansão, 8a andar, Sala 814, 21040-361, Rio de Janeiro, RJ, Brasil.E-mail:<fabricia.pimenta@cdts.fiocruz.br>.
} 


\section{Introdução}

A biotecnologia apresenta soluções para a sociedade em diferentes domínios. Suas contribuições vão desde ferramentas para grandes descobertas cientíicas até soluções médicas que podem abrigar em um único chip (lab-on-a-chip) diversas tecnologias para o diagnóstico instantâneo (poin-of-care). Seu impacto pode também ser observado em áreas das Humanidades, ao se apresentar como um modelo para estudos de pesquisa econômica e social, em face de seu alto impacto inovativo, com importantes repercussões comerciais (FALCIOLA, 2009; MALONEY et al., 2010; THE ORGANISATION FOR ECONOMIC CO-OPERATION AND DEVELOPMENT, 2005).

De acordo com o National Center for Biotechnology Information (NCBI), a biotecnologia é o nicho de conhecimento relacionado ao uso de organismos, células ou componentes derivados, com a finalidade de desenvolver produtos úteis em aspectos técnicos, científicos e clínicos (http://www.ncbi.nlm.nih.gov/mesh/?term=bio technology). A definição claramente evidencia as múltiplas oportunidades de produtos e tecnologias, principalmente a partir do advento da engenharia genética.

Para a Organização para a Cooperação e Desenvolvimento Econômico (OCDE), biotecnologia pode ser explicada por uma simples definição: "a aplicação da ciência e da tecnologia em organismos vivos, assim como em componentes, produtos e modelos derivados, para alterar materiais vivos ou não, com o propósito da produção de conhecimento, bens e serviços". A simples definição abrange toda a biotecnologia moderna, mas também atividades tradicionais e na fronteira do conhecimento. A OCDE

324 ainda preconiza o uso de uma lista não exaustiva de técnicas biotecnológicas como um guia interpretativo para sua definição, quais sejam:

1) DNA/RNA (genômica, farmacogenômica, marcadores genéticos, engenharia genética, sequenciamento/síntese/amplificação de DNA/RNA, perfil de expressão gênica, uso de tecnologia antisense);

2) Proteínas e outras moléculas (sequenciamento/síntese/amplificação de proteínas e peptídeos, incluindo grandes moléculas de hormônios, métodos otimizados de liberação de drogas baseadas em grandes moléculas, proteômica, purificação e isola- mento de proteínas, sinalização e identificação de receptores celulares);

3) Engenharia celular e de cultura de células (cultura de células e tecidos, engenharia biomédica, fusão celular, estimulantes imunes/vacinais, manipulação de embriões);

4) Técnicas de processos biotecnológicos (fermentação por biorreatores, bioprocessamento, biolixiviação, biorremediação, biofiltração e fitorremediação);

5) Vetores (terapia gênica e vetores virais);

6) Bioinformática (construção de banco de dados de genomas, sequências proteicas, modelagem de processos biológicos complexos, incluindo sistemas biológicos);

7) Nanobiotecnologia (aplicação de ferramentas e processos de nano/microfabricação para desenvolvimento de dispositivos para o estudo de biossistemas e aplicação em liberação de drogas, diagnóstico etc.) (THE ORGANISATION FOR ECONOMIC CO-OPERATION AND DEVELOPMENT, 2005).

Associadas ao progresso da biotecnologia e à consequente produção de abundantes oportunidades, a geração, análise e gestão dessas novas informações têm se tornado cada vez mais desafiadoras. Inúmeras iniciativas, tanto públicas quanto privadas, em conjunto, têm diminuído os custos e otimizado o tempo de geração e análise dos dados biológicos. Essas iniciativas têm alcançado um intenso crescimento na quantidade e complexidade da informação biotecnológica disponível tanto para a comunidade científica quanto para a sociedade em geral. Um exemplo típico desse fenômeno é a velocidade do sequenciamento dos genomas, que tipicamente dobra a cada ano, ao passo que os custos experimentam quedas vertiginosas. $E$, nesse sentido, o progresso científico e tecnológico nesse setor é largamente dependente da rápida disseminação e fácil acesso aos dados científicos, em particular aos dados "brutos" de genomas (COMMISSION OF THE EUROPEAN COMMUNITIES, 2002).

Contudo, essa grande quantidade de informação ainda gera empecilhos que adiam ou impedem o melhor uso dos dados. Nitidamente, três circunstâncias merecem destaque: 
1) a informação encontra-se disposta em diferentes formatos, verbais e não verbais, o que inclui artigos, sequências biológicas, documentos de patentes, bases de dados, tabelas, imagens, gráficos etc:;

2) a informação é divulgada por diferentes meios não interoperáveis, ou seja, para que se tenha acesso à informação, o usuário deve obtê-la in loco, e para tanto necessita saber especificamente em qual sistema de informação ou base de dados ela se encontra;

3) a incapacidade de se compararem quantitativa e qualitativamente os dados em nível mundial (FALCIOLA, 2009; FRANÇA, 1997; MULLER, 2007; SIMMONS, 2009; THE ORGANISATION FOR ECONOMIC CO-OPERATION AND DEVELOPMENT, 2005).

Esses fatores aumentam consideravelmente os esforços para que se possa comparar ou compilar a informação existente nas patentes, artigos científicos, literatura cinzenta, produtos e tecnologias, com o intuito de se observarem tendências, novos nichos para desenvolvimento e novas fronteiras do conhecimento (FALCIOLA, 2009; MULLER, 2007).

\section{A patente como fonte de informação}

A patente tem sido considerada uma excepcional fonte de informação científica e tecnológica, na medida em que disponibiliza a informação mais recente sobre o estado da arte e, ainda, oferece informações de caráter legal e comercial.

O documento de patente, em termos gerais, necessariamente deve conter uma descrição técnica da invenção. Essa descrição, naturalmente, apresenta o estado da arte da tecnologia, o problema técnico a ser suplantado e a solução alcançada pela invenção. Mais especificamente, o documento deve descrever o modo pelo qual os inventores alcançaram a solução para o problema técnico, ao apresentar a experimentação laboratorial que consubstancia a solução proposta. A descrição deve ser feita de forma clara e suficiente pelos inventores, a fim de se alcançar um critério legal, qual seja, possibilitar sua realização por técnico no assunto e, ainda, indicar a melhor forma de execução.

Desse modo, espera-se que o documento de patente contenha uma grande quantidade de conhe- cimento técnico-cientifico, e que não seja somente um documento com informações de caráter legal. Entretanto, o desconhecimento, por parte dos pesquisadores, acerca das características técnicas e científicas de um documento de patente perpetua o desinteresse desses profissionais por esse tipo de fonte de informação (FRANÇA, 2007; MUCKE, 2011).

A confiança sobre essa premissa advém de dois aspectos: (1) decorre da falta de cultura em utilizar o sistema de patentes, e (2) procede do entendimento de que a informação contida nas patentes somente se mostra útil em aspectos comerciais, tais como a verificação de infringências e liberdade para operar, e não como uma fonte de informação técnica (BREGONJE, 2005; MENDONÇA; PIMENTA, 2013).

Entretanto, os documentos de patente podem ter diversos empregos como fonte de informação, tanto por aspectos técnicos quanto legais e comerciais, podendo apresentar:

1) tecnologias que estão em domínio público e, portanto, acessíveis a qualquer pessoa que queira desenvolvê-las e/ou comercializá-las, como bem enfatizam Barroso et al. (2003) ao informar que esses documentos podem promover benefícios sociais, tecnológicos e econômicos ao Brasil, favorecendo toda a sociedade (ARAÚJO, 1984; FRANÇA, 2007);

2) as informações mais recentes em dado setor tecnológico. Segundo o banco de dados estatísticos da Organização Mundial da Propriedade Intelectual, em 2014, em todo o mundo, foram depositados 2680900 pedidos de patentes, dos quais 47012 pertencentes ao setor de biotecnologia (WIPO IP STATISTICS DATA CENTER, 2016)

3) uma ampla gama de informação sobre o estado da arte de uma determinada área de conhecimento, uma vez que a patente deve apresentar tanto os empecilhos e entraves a serem resolvidos quanto todas as soluções técnicas. E, dessa forma, pode servir como fonte de ideias para novas pesquisas que aproveitem conhecimentos e experiências, adequando-as às necessidades nacionais (ARAÚJO, 1984; GARCIA DELGADO et al., 2015);

4) a evolução tecnológica do estado da arte em um dado setor tecnológico, apontando novos 
caminhos de pesquisa e desenvolvimento, bem como indicando os temas fronteiriços do conhecimento ou alternativas técnicas à tecnologia protegida (ARAÚJO, 1984; BENSON; MAGEE, 2015);

5) a evolução tecnológica de um país ou região, identificando suas características regionais em termos de economia, recursos naturais, mercado etc.;

6) os parceiros em potencial ou os concorrentes em determinado setor, detentores da tecnologia alvo de licenciamento, transferência ou codesenvolvimento etc.

Quanto ao fato de os documentos de patente apresentarem as informações mais recentes em dado setor tecnológico, essa vantagem é consequência da necessidade de atendimento ao critério de novidade. Isso significa dizer que o conteúdo do pedido de patente não deve ser divulgado, por qualquer meio, antes da data do seu depósito no escritório oficial de propriedade industrial, não se restringindo a barreiras geográficas. Em sentido contrário, se feita a divulgação antes do depósito, independentemente do lugar ou meio, não mais se alcançará o critério da novidade. Assim, idealmente, a primeira publicação de uma nova tecnologia e de seus aperfeiçoamentos é feita em um documento de patente.

Essa premissa se torna tão verídica para determinados setores que alguns estudos asseveram que cerca de $80 \%$ da informação técnico-científica divulgada em um documento de patente não é divulgada em qualquer outro meio (BREGONJE, 2005). Em outro estudo, Terapane (1978) concluiu, após analisar 435 patentes estadunidenses, que $70 \%$ das novas tecnologias não foram publicadas posteriormente. Liebesny et al. (1974) concluíram que somente 5\% da informação técnica contida nas patentes foi publicada posteriormente em literatura não patentária. Berks (1997) demonstrou que importantes moléculas somente são publicadas em literatura não patentária meses ou anos após o patenteamento. Mucke (2011) enfatiza que mais de dois terços dos pedidos de patente nas áreas de hipertensão, aterosclerose ou aneurisma não foram publicados em um artigo revisado por pares.

Não há relatos sobre a dinâmica de publicação dos resultados de pesquisas em biotecnologia. E, por certo, cada setor acadêmico ou de desenvolvimento tecnológico tem suas particularidades quanto à publicização e divulgação dos seus resultados. Contudo, mostra-se evidente que nem toda a informação técnico-científica está publicada na literatura científica padrão, qual seja, artigos científicos, revisões, teses, dissertações, monografias etc. $E$, nesse mesmo sentido, a literatura patentária não deve ser desprezada sob a alegação de ser demasiadamente jurídica ou de difícil compreensão (o que realmente pode ser verdade) (MENDONÇA; PIMENTA, 2013). Exatamente pelo fato de conter grande quantidade de informação, por vezes não disponível em outro meio de divulgação, tanto por ser publicada exclusivamente no sistema de patentes, quanto por estar na fronteira do conhecimento, o documento de patente mostra-se uma fonte substancial de informação para o desenvolvimento de pesquisas científicas.

As patentes na área de biotecnologia em saúde tiveram grande destaque no final da década de 1990, devido à imensidão de pedidos relacionados ao genoma humano (THE ORGANISATION FOR ECONOMIC CO-OPERATION AND DEVELOPMENT, 2005). Em termos absolutos, foram publicados 38152 pedidos de patentes do setor biotecnológico em 2004, e 47012 em 2014. Em termos relativos, as patentes biotecnológicas representaram mundialmente $2,4 \%$ dos portfólios de patentes em 2004, contra 1,7\% em 2014.

No entanto, ademais de sua importância em termos quantitativos, as patentes biotecnológicas na área da saúde podem ainda ser exploradas por apresentarem:

a) novos compostos e suas formas polimórficas, novas formulações ou apresentações farmacêuticas, incluindo as estratégias de evergreening das indústrias farmacêuticas;

b) novos marcadores para diagnóstico, prognóstico ou medicina personalizada;

c) novas tecnologias de diagnóstico, com seus controles e kits, para doenças transmissíveis e não transmissíveis;

d) novos marcadores para bioterapias preventivas ou curativas, tais como vacinas e tratamentos com anticorpos monoclonais; 
e) novas metodologias para triagem de drogas, através de high throughput screening ou in silico por meio da bioinformática;

f) novas técnicas de proteômica, genômica e metabolômica para diagnóstico, prognóstico ou estudos epidemiológicos;

g) novos usos para compostos bem estabelecidos no mercado, ou para receptores celulares como alvos terapêuticos ou para redes de interações bioquímicas intra e intercelulares;

h) novas tecnologias para provas de conceito, testes pré-clínicos e farmacovigilância, dentre muitas novas tecnologias.

Ressalvadas as diferenças legais de maior ou menor restrição entre os países para concessão de patentes para biotecnologias, são patenteáveis:

- genes e moléculas de ácidos nucleicos (exemplo: genes relacionados a doenças, como insumo para diagnóstico, ou moléculas para terapia, como vacina de DNA ou RNA de interferência);

- proteínas (exemplo: insulina, eritropoietina para terapias, receptores celulares para triagem de drogas);

- enzimas (exemplo: glucocerebrosidase recombinante para terapia de reposição);

- anticorpos (exemplo: para tratamento de câncer, insumos para laboratórios e testes de diagnóstico);

- vírus (exemplo: virus like particles, ou sequências virais para testes diagnósticos e vacinas, sistema de expressão e terapias);

- células (exemplo: células hematopoiéticas para tratamento da leucemia, linfócitos para imunoterapia);

- microrganismos (exemplo: bactérias e leveduras como plataformas de produção de proteínas vacinais ou terapêuticas, ou de insumos laboratoriais);

- plantas (exemplo:como plataformas para expressão de proteínas);

- animais (exemplo: modelos de doença para pesquisa, como o oncomouse, capaz de desenvolver câncer de mama, ou animais knockout, que não expressam determinadas características; doadores para xenotransplantes; produtores de leite ou outros insumos com medicamentos) (ÖZDEMIR, 2009).
Ao considerar que a Fundação Oswaldo Cruz (FIOCRUZ) tem se apresentado, no cenário brasileiro, como uma instituição de destaque na produção de conhecimento, principalmente no setor de biotecnologia para a saúde, o presente trabalho buscou analisar como a comunidade científica da Fundação acolheu o uso de documentos de patente como fonte de informação em seus trabalhos acadêmicos. E, para tal, analisou os documentos de patente citados como referência bibliográfica para construção da produção acadêmica dos diversos programas de pós-graduação da FIOCRUZ.

\section{Procedimentos metodológicos}

A FIOCRUZ está presente em 10 estados, com 16 unidades técnico-científicas, voltadas para ensino, pesquisa, inovação, assistência, desenvolvimento tecnológico e extensão no âmbito da saúde. Dentre as unidades, há aquelas que agregam maior habilidade para desenvolvimento tecnológico e inovação de produtos e processos para a saúde, enquanto outras se voltam para o desenvolvimento das Humanidades. Entretanto, todas apresentam vocação para a formação de mestres e doutores.

Em razão dessas idiossincrasias, o presente estudo buscou analisar as unidades que apresentassem a vocação de produzir conhecimento patenteável. Para tal, analisou a produção acadêmica de doutoramento das seguintes unidades técnico-científicas: Instituto Aggeu Magalhães (IAM) em Pernambuco, Instituto Carlos Chagas (ICC) no Paraná, Instituto Gonçalo Moniz (IGM) na Bahia, Instituto René Rachou (IRR) em Minas Gerais, Instituto Nacional de Controle de Qualidade em Saúde (INCQS), Instituto Nacional de Infectologia Evandro Chagas (INI), Instituto Nacional de Saúde da Mulher, da Criança e do Adolescente Fernandes Figueira (IFF) e Instituto Oswaldo Cruz (IOC), no Rio de Janeiro. Para as unidades que não possuem pós-graduação em nível de doutorado, o Instituto de Tecnologia em Fármacos (Farmanguinhos) e o Instituto de Tecnologia em Imunobiológicos (Biomanguinhos), ambos no Rio de Janeiro, a produção acadêmica analisada foram as dissertações de mestrado profissional. 
A partir de conhecimentos e técnicas do campo da cientometria, a fim de melhor compreender o processo de comunicação científica (VAN RAAN, 1997; VANTI, 2002), os dados utilizados foram coletados por meio do Repositório Institucional da FIOCRUZ, denominado ARCA. Em seu sítio eletrônico, (http://www.arca. fiocruz.br/), a partir de cada comunidade representativa das unidades técnico-científicas, foram buscados na coleção "Teses de Doutorado" ou, quando cabível, “Dissertações de Mestrado", os metadados de toda a produção constante na coleção. Os metadados, inclusive o hiperlink para o objeto eletrônico, foram extraídos e analisados utilizando o programa Excel.

Em seguida, a partir do hiperlink de cada entrada de dados, foi avaliado o arquivo eletrônico, em formato portable document format, de cada tese ou dissertação. A avaliação ocorreu de duas formas distintas, com o intuito primaz de se aumentar a revocação e a precisão da busca. Primeiramente, o termo "patent" foi buscado no documento analisado, a partir de ferramenta de busca do próprio programa. A escolha do termo deu-se pelo fato de contemplar tanto documentos de patente em português, quanto em outros idiomas que utilizam o mesmo radical linguístico. Entretanto, observou-se que, em alguns casos de citação de patentes, o termo não era utilizado. Nesse cenário, optou-se por, paralelamente, realizar uma segunda avaliação, buscando, item a item, referências de documentos de patente na seção "Referências Bibliográficas" de cada documento.

Vale evidenciar que o repositório institucional da FIOCRUZ ARCA mostrou-se uma ferramenta valiosa para estudos dessa natureza. A base de dados revelou-se hábil para a busca e extração dos dados, permitindo o acesso aberto e livre à produção intelectual da FIOCRUZ, promovendo a disseminação e visibilidade do conhecimento, conforme bem versam os princípios da Política de Acesso Aberto ao Conhecimento da FIOCRUZ (FUNDAÇÃO OSWALDO CRUZ, 2014)

O corpus analisado foi constituído por 487 teses de doutorado e 69 dissertações de mestrado profissional, totalizando 556 documentos. Os documentos apresentaram a produção acadêmica dos cursos de pós-graduação da FIOCRUZ entre os anos 2003 e 2015 (Figura 1). Entretanto, deve-se enfatizar que o conjunto analisado pode não contemplar toda a produção do período, uma vez que o repositório institucional vem sendo povoado em um longo processo, no que tange aos documentos publicados anteriormente à vigência da Política de Acesso Aberto ao Conhecimento da FIOCRUZ, em 2014.

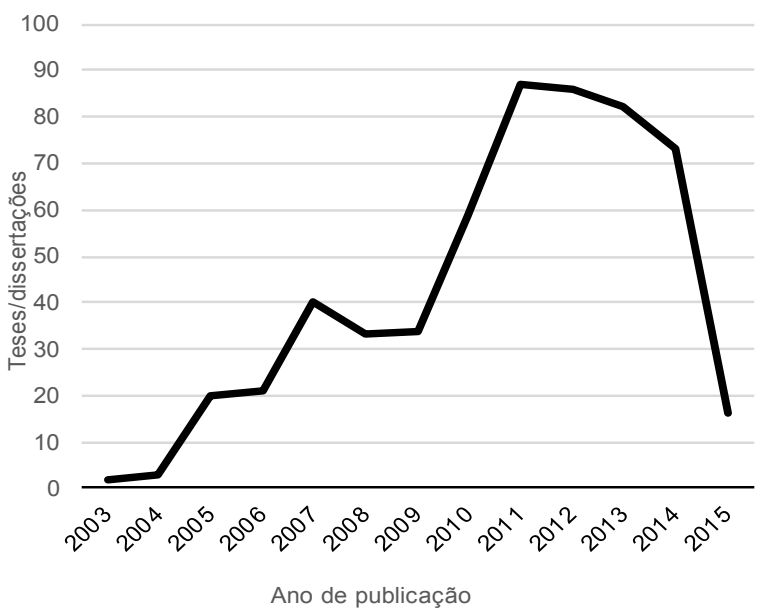

Figura 1. Produção acadêmica de teses e dissertações da Fundação Oswaldo Cruz analisadas quanto ao uso de citações de patentes.

Fonte: Elaborada pela autora (2016).

\section{Resultados}

No universo amostral estudado, somente 16 (2,87\%) teses/dissertações utilizaram, ao menos, uma patente como fonte de informação científica ou tecnológica. Ao se tentar observar um padrão de utilização, pode-se verificar que, dentre as 16 teses/ dissertações, dez incluíram uma única patente como referência bibliográfica, enquanto duas incluíram duas patentes, uma incluiu quatro patentes, outra incluiu cinco patentes, ainda outra incluiu seis patentes e outra incluiu dez patentes.

A partir desse primeiro resultado, pode-se nitidamente concluir que as patentes não são utilizadas como fonte de informação científica ou tecnológica nos trabalhos acadêmicos oriundos da FIOCRUZ. O exíguo número de citações de patentes fica mais evidente ao se constatar que em uma tese se utiliza, em média, mais de 100 referências. Ou seja, o índice de utilização de documentos de patente proporcionalmente aos demais tipos documentais é insignificante. 


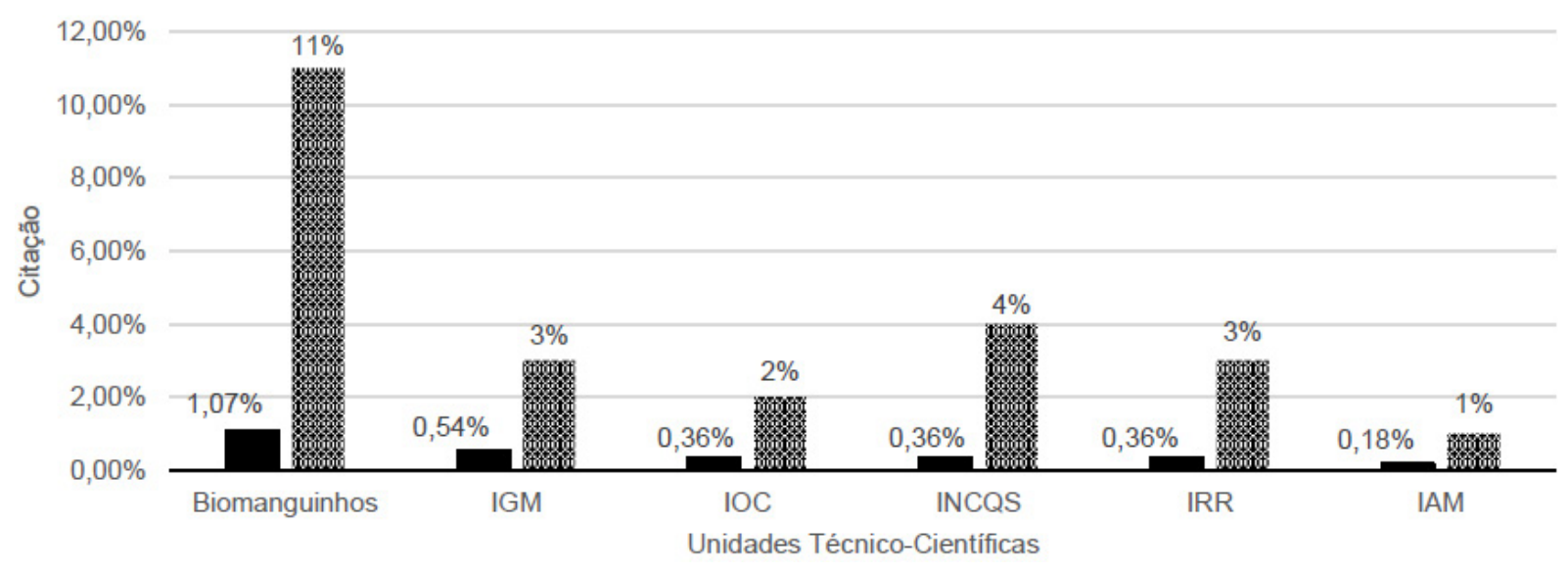

Figura 2. Citação de documentos de patente como fonte de informação em trabalhos acadêmicos, por unidades técnico-científicas da Fundação Oswaldo Cruz.

Nota: Primeira série de dados: percentual de teses/dissertações que citaram patentes de cada unidade técnico-científica em relação a todo o corpus da pesquisa; Segunda série de dados: percentual de teses/dissertações que citaram patentes de cada unidade técnico-científica em relação ao total da própria unidade. Biomanguinhos: Instituto de Tecnologia em Imunobiológicos; IGM: Instituto Gonçalo Moniz; IOC: Instituto Oswaldo Cruz; INCQS: Instituto Nacional de Controle de Qualidade em Saúde; IRR: Instituto René Rachou; IAM: Instituto Aggeu Magalhães.

Fonte: Elaborada pela autora (2016).

Ao se estudar se o exíguo número de patentes utilizadas poderia ser consequência de um comportamento institucional exclusivo de determinada unidade técnico-científica, foi analisada a participação percentual em relação a todo o corpus da pesquisa e em relação ao total da própria unidade (Figura 2). Pode-se observar que Biomanguinhos foi a unidade que mais utilizou as patentes como fonte de informação para a sua produção acadêmica, com cerca de 6 dissertações, seguido de IGM, INCQS, IOC, IRR e IAM com 3, 2, 2, 2 e 1 teses, respectivamente.

Ao se analisar o índice de utilização das patentes em relação ao total da própria unidade, observa-se que somente $11 \%$ das dissertações de mestrado profissional de Biomanguinhos citaram alguma patente no rol de documentos utilizados nas referências bibliográficas. Já nas unidades IGM, INCQS, IOC, IRR e IAM observam-se menores índices, com 4\%, 3\%, 3\%, 2\% e 1\%, respectivamente. As demais unidades não utilizaram as patentes em suas produções acadêmicas.

Em outra perspectiva, não se observa nenhum padrão de citação das patentes, nem em relação aos orientadores, nem mesmo em relação aos programas de pós-graduação. O que significa dizer que não há estímulo por parte dos orientadores, tampouco por parte dos programas de pós-graduação para o uso de documentos de patente no desenvolvimento dos trabalhos acadêmicos.

Em relação às patentes citadas nas teses/dissertações, foram identificados 39 documentos de patente de diferentes países, majoritariamente dos Estados Unidos, com 24 documentos. Também foram citados pedidos de patente depositados no Brasil, Espanha, Israel, França e Canadá, além da Comunidade Europeia e via Tratado de Cooperação em Matéria de Patentes.

Quanto ao aspecto temporal, as patentes citadas foram publicadas ou depositadas no período entre 1936 e 2010, com maior concentração na década de 2000 o que pode evidenciar o uso desses documentos com a finalidade de citar importantes marcos temporais de determinada tecnologia, e não de averiguar os avanços fronteiriços do conhecimento. Tal assertiva pode ser mais bem evidenciada na Figura 3, que apresenta a variação de tempo entre a publicação de cada um dos 39 documentos de patente e sua utilização como referência bibliográfica. Em média, o documento de patente foi citado 12 anos após sua publicização, com variação entre 1 e 74 anos. 


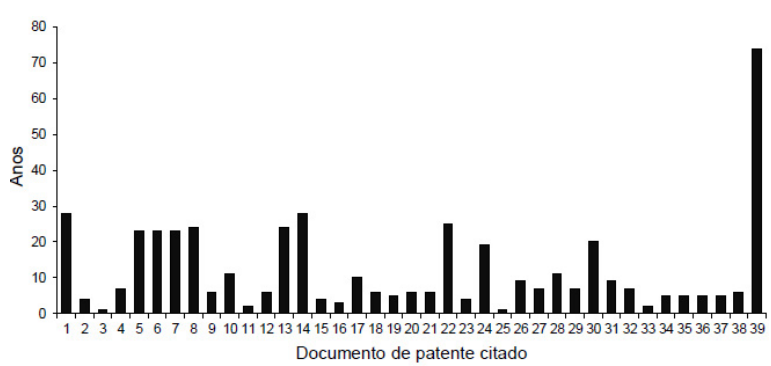

Figura 3. Variação temporal, em anos, entre a publicação dos 39 documentos de patente citados e a publicação da tese/ dissertação citante.

Fonte: Elaborada pela autora (2016)

\section{Discussão}

O pesquisador, durante sua trajetória acadêmica, aprende que a publicação cientifica é o principal instrumento de reconhecimento nas ciências. São exceções os cursos de graduação ou pós-graduação que introduzem o conhecimento sobre o sistema de patentes, principalmente nas Ciências da Saúde ou Biológicas (AMORIM-BOHRER et al., 2007; PAULA FILHO; SOUZA, 2009). Entretanto, é primordial que o conhecimento sobre patentes faça parte da formação acadêmica dos alunos de ciências, a fim de assegurarIhes as habilidades necessárias para o desenvolvimento de suas carreiras científicas (MacMILLAN, 2006).

MacMillan (2006, p.149), em estudo intitulado " [...] the place for patents in information literacy in the sciences", evidencia alguns importantes aspectos a serem considerados, tais como o papel central de professores sensíveis ao uso das patentes como fonte de informação; a introdução do tema aos alunos, no início de sua carreira acadêmica, para que possam utilizá-lo em seus trabalhos finais; e instruções orientadas para os interesses dos alunos, de modo a ampliar sua atenção sobre o tema.

Mendonça e Pimenta (2013) elencam cinco condições que contribuem para que os pesquisadores subutilizem o sistema de patentes no Brasil. As autoras enfatizam que são situações limitantes:

- a falta do aprendizado sobre o sistema de patentes desde a graduação e ainda na pós-graduação;

- a peculiar redação de um documento de patente, o "patentês";

- a exigência de uma rápida publicação científica para uma boa avaliação profissional;
- a carência de infraestrutura especializada dentro da instituição de ciência e tecnologia para o processo de patenteamento;

- o longo e intrincado processo de patenteamento.

Um relatório da Comission of the European Communities alerta que o setor industrial considera que os cientistas não estão suficientemente conscientes da importância do sistema de patentes e da política relativa à propriedade intelectual (COMMISSION OF THE EUROPEAN COMMUNITIES, 2002). Bregonje (2005) aborda que os pesquisadores acreditam que as patentes não são relevantes para o desenvolvimento de seus trabalhos e, portanto, não as utilizam como fonte de informação. Blossey (2002), ao publicar um comentário na Nature Materials, intitulado "Read patents, not just papers", enfatiza o entendimento dos pesquisadores de estigmatizarem a patente como um documento meramente comercial, voltado ao lucro e desinteressante sob o ponto de vista científico.

Os resultados ora apresentados ratificam todos os estudos anteriores, ao evidenciar um cenário de completo preterimento dos documentos de patente como fonte de informação científica e tecnológica, nas produções acadêmicas dos programas de pósgraduação da FIOCRUZ. Esse panorama se torna mais drástico quando se observa que as exíguas patentes citadas não representam tecnologias na fronteira do conhecimento, o que implica dizer que as citações descrevem o estado da arte em um viés histórico, e não tecnológico.

Ainda vale enfatizar que o sistema de proteção dos direitos de propriedade intelectual se expande vertiginosamente, publicando cerca de 2680900 documentos de patente somente em 2014. A não exploração desse enorme volume de informação implica, especialmente para o Brasil, desperdício de investimentos de Pesquisa Desenvolvimento e Inovação, na medida em que se deixa de apreciar o que já está posto no estado da arte, culminando em pesquisas repetidas e atraso no desenvolvimento científico e tecnológico do país.

A produção de conhecimento em biotecnologia, principalmente a partir da modificação de organismos vivos por meio de técnicas de engenharia genética, nas décadas de 1970 e 1980, abriu novas 
possibilidades para o desenvolvimento de novos produtos e processos. Ao inserirem genes sintéticos ou mesmo de outros organismos em um sistema vivo de expressão, ou seja, uma bactéria, levedura ou célula de planta, os cientistas puderam transpor barreiras para a criação de novas drogas baseadas em genes humanos e animais transgênicos com novas e melhoradas propriedades. Esses avanços tecnológicos rapidamente despertaram o interesse para as possibilidades comerciais e para as vantagens de protegê-los via sistema de patentes. Passados mais de vinte anos, uma imensidão de genes, fragmentos de RNA, quimeras e proteínas têm sido objeto de milhares de pedidos de patentes.

Muitas iniciativas, tanto públicas quanto privadas, têm investido em pesquisas para aplicação do conhecimento genético no processo de descoberta, desenvolvimento e novos usos de medicamentos. 0 domínio tecnológico das técnicas para o sequenciamento do genoma humano, a produção de proteínas sintéticas, o isolamento das células-tronco e a clonagem de células humanas trouxeram uma avalanche de milhares de pedidos de patente para novas drogas, vacinas, testes diagnósticos, insumos médicos e terapias (THE NUFFIELD COUNCIL ON BIOETHICS, 2002; LOPEZ, 2002).

Nesse mesmo sentido, a FIOCRUZ vem protegendo suas tecnologias desenvolvidas via sistema de patentes. A Fundação tem, atualmente, em seu portfólio de patentes, 137 tecnologias protegidas a partir de 137 documentos de patente no território nacional, e cerca de 344 documentos em diversos países e regiões, tais como Austrália, África do Sul, Canadá, China, Colômbia, Coreia do Sul, Cuba, Espanha, Estados Unidos da América, Europa, Japão, México, Peru e Rússia (SILVA, 2016). Apesar desse amplo quantitativo, pode- -se observar que nem mesmo os inventores pesquisadores da FIOCRUZ utilizam, de forma corriqueira, as patentes nos trabalhos acadêmicos de seus alunos. Nem mesmo as unidades técnico-científicas abrangidas neste estudo, com vocação mais direcionada para a pesquisa translacional, têm direcionado seus alunos a buscarem informação científica nos documentos de patente.

\section{Conclusão}

Os dados evidenciam que, apesar de toda a sua importância como fonte de informação para a pesquisa biotecnológica em saúde, a patente não tem sido citada nos trabalhos acadêmicos. Estudos adicionais são necessários para que se possa observar se esse comportamento é peculiar da FIOCRUZ ou se pode ser extrapolado para outras instituições produtoras de conhecimento no Brasil.

Ainda se conclui que o conhecimento sobre patentes deve ser incentivado em todos os níveis de formação do pesquisador, desde o técnico ao doutoramento, e até mesmo no transcorrer de sua vida profissional. A necessidade desse conhecimento é premente para a construção de um profissional, ou mesmo pesquisador, mais hábil para produzir ciência, tecnologia e inovação, e sinaliza a necessidade de criação e inserção de disciplinas curriculares e de um programa institucional de engajamento inserido e consubstanciado na política de inovação da instituição. Nesse sentido, o papel dos núcleos de inovação tecnológica e dos analistas de patentes no processo de conscientização dos professores/pesquisadores e de seus alunos é de primazia angular.

\section{Referências}

AMORIM-BOHRER, M. B. et al. Ensino e pesquisa em propriedade intelectual no Brasil. Revista Brasileira de Inovação, v. 6, n. 2, p. 281-310, 2007. Disponível em: <http://ocs.ige.unicamp.br/ojs/rbi/article/view/321 >. Acesso em: 21 set. 2016.

ARAÚJO, V. M. R. H. Uso da informação contida em patentes nos países em desenvolvimento. Ciência da Informação, v. 13, n. 1, p. 53-56, 1984.

BARROSO, W. B. G. et al. Analysis of a database of public domain Brazilian patent documents based on the IPC. World Patent Information, v. 25. p. 63-69, 2003. Available from:
<http://www.quoniam.info/competitive-intelligence/PDF/ publications/2003/WPI_2003.pdf>. Cited: Sept. 21, 2016.

BENSON, C. L.; MAGEE, C. L. Quantitative determination of technological improvement from patent data. PLOS ONE, v. 10, n. 4, e0121635, 2015. Available from: <http://journals.plos. org/plosone/article?id=10.1371\%2Fjournal.pone.0121635>. Cited: Sept. 21, 2016.

BERKS, A. H. Competitive intelligence value of patents vs. other literature sources for drug compounds. In: ACS NATIONAL MEETING, 213., 1997, San Francisco. Annals... San Francisco, San Francisco: ACS, 1997. (Book of Abstracts). 
BLOSSEY, R. Read patents, not just papers. Nature Materials, v. 1, p. 199-201, 2002.

BREGONJE, M. Patents: A unique source for scientific technical information in chemistry related industry. World Patent Information, v. 27, n. 4, p. 309-315, 2005. Available from: $<$ http://www.sciencedirect.com/science/article/pii/S017221 9005000736>. Cited: Sept. 21, 2016.

COMMISSION OF THE EUROPEAN COMMUNITIES. Report from the Commission to the European Parliament and Council - An assessment of the implications for basic genetic engineering research of failure to publish, or late publication of, papers on subjects which could be patentable as required under Article 16(b) of Directive 98/44/EC on the legal protection of biotechnological inventions [SEC(2002) 50]. 2002. Available from: <http://eur-lex.europa.eu/legal-content/EN/TXT/HTML/ ?uri=CELEX:52002DC0002\&from=EN>. Cited: Sept. 21, 2016.

FALCIOLA, L. Searching biotechnology information: A case study. World Patent Information, v. 31, n. 1, p. 36-47, 2009. Available from: <http://www.sciencedirect.com/science/article/pii/S01722 19008000598>. Cited: Sept. 21, 2016

FUNDAÇÃO OSWALDO CRUZ. Portaria da Presidência n. 329/ 2014 de 31 de março de 2014. Institui a Política de Acesso Aberto ao Conhecimento, visando garantir à sociedade o acesso gratuito, público e aberto ao conteúdo integral de toda obra intelectual produzida pela Fiocruz. Rio de Janeiro: Fiocruz, 2014. Disponível em: <https://portal.fiocruz.br/sites/ portal.fiocruz.br/files/documentos/portaria_-_politica_de_ acesso_aberto_ao_conhecimento_na_fiocruz.pdf >. Acesso em: 21 set. 2016

FRANÇA, R. O. Patente como fonte de informação tecnológica. Perspectivas em Ciência da Informação, v. 2, n. 2, p. 235-264, 1997. Disponível em: <http://portaldeperiodicos.eci.ufmg.br/ index.php/pci/article/view/636/425>. Acesso em: 21 set. 2016.

FRANÇA, R. O. A patente. In: CAMPELLO, B. S.; CENDÓN, B. V.; KREMER, J. M. Fontes de Informação para pesquisadores e profissionais. Belo Horizonte: UFMG, 2007. p. 153-182.

GARCIA DELGADO, B. M.; DI FABIO ROGLIA, J. L.; VIDAL CASANOVA, J. Información de patentes: impacto en el acceso a los medicamentos. Revista Cubana de Información en Ciencias de la Salud, v. 26, n. 1, p. 3-19, 2015. Disponible en: <http://scielo.sld.cu/scielo.php?script=sci_arttext\&pi$d=$ S2307-21132015000100002>. Acceso: 21 set. 2016.

LIEBESNY, F. et al. The scientific and technical information contained in patent specifications. The extent and time factors of its publication in other forms of literature. Inform Scientist, v. 8, n. 4, p. 165-177, 1974.

LOPEZ, J. S. Should genetic code be patented? Law and Society Review at UCSB, v. 1, 2002.

MACMILLAN, D. Patently obvious: The place for patents in information literacy in the sciences. Research Strategies, v. 20, n. 3, p. 149-161, 2006. Available from: <http://www. sciencedirect.com/science/article/pii/S0734331006000073>. Cited: Sept. 22, 2016.

MALONEY, T. P. et al. Intellectual property in drug discovery and biotechnology. In: ABRAHAM, D. J.; ROTELLA, D. P. Burger's medicinal chemistry, drug discovery, and development. 7. ed. New Jersey: John Wiley \& Sons, 2010. p. 101-186.
MENDONÇA, G. C.; PIMENTA, F. P. Registro de patente deve ser disciplina de graduação. Revista Ensino Superior, v. 11, p. 2328, 2013. Disponível em: <https://www.revistaensinosuperior. gr.unicamp.br/artigos/registro-de-patente-deve-serdisciplina-de-graduacao>. Acesso em: 21 set. 2016.

MUCKE, H. A. M. Relating patenting and peer-review publications: An extended perspective on the vascular health and risk management literature. Vascular Health and Risk Management, v. 7, p. 265-272, 2011. Available from: <https://www.ncbi.nlm.nih.gov/pmc/articles/PMC3096506/>. Cited: Sept. 21, 2016.

MULLER, S. P. M. A ciência, o sistema de comunicação científica e a literatura científica. In: Campello, B. S.; Cendón, B. V.; Kremer, J. M. Fontes de Informação para pesquisadores e profissionais. Belo Horizonte: UFMG, 2007. p. 17-21.

ÖZDEMIR, A. Patenting biotechological inventions in Europe and US. Ankarabar Review, v. 1, p. 40-63, 2009. Available from: <http://www.ankarabarosu.org.tr/siteler/AnkaraBarReview/ tekmakale/2009-1/5.pdf>. Cited: Sept. 21, 2016.

PAULA FILHO, H.; SOUZA, C. G. Graduate formation in intellectual property in Brazil: A study based on academic production of thesis and dissertations. Journal of Technology Management and Innovation, v. 4, n. 2, p. 154-163, 2009. Available from: $<$ https://www.jotmi.org/index.php/GT/article/view/cas23>. Cited: Sept. 21, 2016.

TERAPANE, J. F. A unique source of information. Chemtech, v. 8, n. 5, p. 272-276, 1978.

SILVA, A. Perfil de patentes. Rio de Janeiro: FIOCRUZ, 2016. (Observatório em Ciência, Tecnologia e Inovação em Saúde). Disponível em: <http://observatorio.fiocruz.br/indicadores/ perfil-dos-pedidos-de-patente>. Acesso em: 20 jul. 2017.

SIMMONS, E. S. "Black sheep" in the patent family. World Patent Information, v. 31, n. 1, p.11-18, 2009. Available from: <http:// www.sciencedirect.com/science/article/pii/S017221900800 104X>. Cited: Sept. 21, 2016.

THE NUFFIELD COUNCIL ON BIOETHICS. The ethics of patenting DNA: A discussion paper. London: Nuffield Council on Bioethics, 2002. Available from: <http://nuffieldbioethics.org/ wp-content/uploads/2014/07/The-ethics-of-patentingDNA-a-discussion-paper.pdf>. Cited: Sept. 21, 2016.

THE ORGANISATION FOR ECONOMIC CO-OPERATION AND DEVELOPMENT. A framework for biotechnology statistics. Paris: OECD, 2005. Available from: <http://www.oecd.org/sti/sci-tech/ 34935605.pdf>. Cited: Sept. 22, 2016.

VAN RAAN, A. F. J. Scientometric: State-of-art. Scientometrics, v. 38, n. 1, p. 205-2018, 1997. Available from: <http://link.springer. com/article/10.1007/BF02461131 >. Cited: March 15, 2017.

VANTI, N. A. P. Da bibliometria à webometria: uma exploração conceitual dos mecanismos utilizados para medir o registro da informação e a difusão do conhecimento. Ciência da Informação, v. 31, n. 2, p. 152-162, 2002. Disponível em: <http://www.scielo.br/pdf/ci/v31n2/12918.pdf>. Acesso em: 15 mar. 2017.

WIPO IP STATISTICS DATA CENTER. Patent publications by technology. Switzerland: WIPO, 2016. Available from: $<$ http://ipstats.wipo.int/ipstatv2/editlpsSearchForm. htm?tab=patent>. Cited: Sept. 21, 2016. 